Forecasting of Dangerous Influence of Avermectin Insecticides to Human Organism Using Surface and Groundwater for Drinking

\title{
Forecasting of Dangerous Influence of Avermectin Insecticides to Human Organism Using Surface and Groundwater for Drinking
}

\author{
Anna M. Antonenko*, Olena P. Vavrinevych \\ Hygiene and Ecology Department № 1 of 0. O. Bogomolets National Medical University, \\ Peremohy av., 34, Kyiv, Ukraine, 03057
}

\section{Bohdan I. Shpak}

Registration and Regulation Department of Syngenta LLC, Kozatska str., 120/4, Kyiv, Ukraine, 03680

\section{Sergii. T. Omelchuk}

Hygiene and Ecology Institute of O. O. Bogomolets National Medical University, Peremohy av., 34, Kyiv, Ukraine, 03057

\section{*Corresponding author: antonenko1985@ukr.net}

More than 400 types of harmful organisms cause damage to agricultural crops. Insecticides occupy one of the last places in the structure of the pesticides assortment among formulations authorized for application in the world. However, they occupy the first place according to their toxicity and the hazard effect to the human body. The purpose of our study was comparative hygienic assessment of soil stability, surface and groundwater migration potential, prediction of dangerous effects of insecticides-avermectins on the human body after using surface and groundwater for drinking needs. For an integral assessment of the potential danger of pesticide exposure to the human body after consumption of water from surface and groundwater supply sources, a scale of four gradations was used. It includes the LEACH (index of potential contamination of groundwater and river waters), half-life period $\left(\mathrm{DT}_{50}\right)$ in water and an allowable daily dose (ADD) or acceptable daily intake (ADI). It has been established that in different soil and climatic conditions, according to the LEACH index, there is a very low risk of groundwater and surface water contamination. This is due to their relatively high solubility in water, low soil persistence and very 
high values of the organic carbon sorption coefficient. According to the IIWH index (integral index of water hazard), abamectin and emamectin benzoate in different soil and climatic conditions are moderately hazardous for a person after consumption of contaminated drinking water (class 3); emamectin benzoate in the soil and climatic conditions of Ukraine is hazardous (class 2). It is necessary to monitor carefully the boundaries of sanitary-protective areas from treated areas to water bodies, and control the process of exploitation of water supply sources, especially decentralized in rural areas. In regions with intensive agricultural production, it is recommended to use the IIWH index to make a decision about the necessity of monitoring research on insecticides in water.

Keywords: groundwater, surface water, hazard, leaching, avermectin.

\section{Introduction}

To date, it is known that more than 400 types of harmful organisms cause damage to agricultural crops (Pesticides List, 2012). That is why the technological need in the plant protection products, including insecticides, for agricultural producers is increasing constantly: on average, the annual requirement of countries for pesticides is about 33-35 thousand tons of formulations (Pesticides List, 2012). Each year their assortment is expanding, and volumes of application increase (Pesticides List, 2018; EU Pesticides Database, 2019).

Avermectins refer to a new class of bio-insecticide macrocyclic lactones that are a natural product synthesized by the soil microorganism Streptomyces avermitilis. There are 4 compounds in this class: abamectin, emamectin benzoate, milbemectin, and lipimectine (IRAC, 2014). The compounds belong to the plant protection means of biological origin. The nature of their toxic effects on the warm-blooded animals and humans and also the environmental fate features are due to their origin (Eloisa Dutra Caldas, 2008). Formulations based on the first two compounds, as most effective at lesser manifestations of toxicity, are registered and widely used in Ukraine and abroad (Pesticides List, 2018; EU Pesticides Database, 2019).

At the same time, chemical means for harmful organism control, i.e., pesticides, belong to hazardous substances of anthropogenic origin entering the environment, along with industrial waste. The volume of these substances that are biologically active and more often highly toxic to human and animal organisms used annually in world practice now exceeds 2 million tons. According to UNESCO, pesticides in the total amount of pollution of the Earth's biosphere occupy the $8^{\text {th }}-9^{\text {th }}$ place after such substances as petroleum products, surfactants, phosphates, mineral fertilizers, heavy metals, and nitrogen (UNESCO WWAP, 2017; IIWQ, 2019).

Insecticides occupy one of the last places in the structure of the pesticides assortment among formulations authorized for application in the world (EU Pesticides Database, 2019). However, they occupy the first place according to their toxicity and the hazard effect to the human body (Deepu et al., 2009; Grafton-Cardwell et al., 2005). It should be noted that the characteristic feature of insecticides is their pronounced effect on the nervous system (Grafton-Cardwell et al., 2005). Therefore, it is necessary to consider not only the parameters of stability and migration of insecticides, but also indicators of their toxicity, when assessing the risk of insecticide penetration into the human body from environmental objects, among which in the first place are sources of water supply (surface and groundwater).

\section{Materials and methods}

The behaviour of the investigated compounds in the soil was performed by the method of natural hygienic experiment. The dynamics of residual amounts of abamectin and emamectin benzoate in the soil during their application on crops during 3 growing seasons in different soil and climatic zones of Ukraine were studied.

Soil samples (top layer $10 \mathrm{~cm}$ thick) were taken by the envelope method from the first day after treatment and then at certain intervals 5-6 times during the growing season until harvest. Determination of residual amounts of studied substances in soil was performed by high-potential liquid chromatography (HPLC) methods according to current guidelines in Ukraine. 
Physico-chemical properties, environmental persistency indices and toxicometric parameters of the studied abamectin and emamectin benzoate insecticides are given in Table 1 (BPDB: Bio-Pesticides DataBase, 2019).

The parameters of persistence in water of investigated active substances of the avermectine class, as well as their main toxicological properties, are given according to the literature data (BPDB: Bio-Pesticides DataBase, 2019), and soil stability parameters are given according to the literature data (BPDB: Bio-Pesticides DataBase, 2019) and based on the results of own field studies conducted in soil and climatic conditions of Ukraine for 10 years (Table 1). The half-life period $\left(\mathrm{DT}_{50}\right)$ of the studied substance in the soil was calculated for assessment of their behaviour in Ukraine's agrocenoses. For this purpose, a method of mathematical modelling was used, which involves the estimated reproduction of the pesticide destruction processes in soil based on actual data. It allows predicting their persistence.

The Ukrainian classification of pesticides according to the degree of hazard as of State Standard 8.8.1.002-98 (Pesticides: Hazard Classification, 1998) was used for evaluation of our own research results and determination of the class of hazard for abamectin and emamectin benzoate according to stability and migration potential in the soil. This classification foresees the separation of substances by stability in the soil in 4 classes: 1 - highly persistent ( $\mathrm{DT}_{50}$ over 120 days), 2 - persistent $\left(\mathrm{DT}_{50}=31-60\right.$ days), 3 - moderately persistent ( $\mathrm{DT}_{50}=11-30$ days), and $4-$ not persistent ( $\mathrm{DT}_{50}$ less than 11 days).

In addition, Soil Survey and the Land Research Center Classification of Cranfield University was used (SSLRC classification, 1997). This classification foresees the separation of substances by stability in the soil in 3 classes:

Table 1. Physico-chemical properties, environmental persistency indices and toxicometric parameters of the studied insecticides (BPDB, 2019)

\begin{tabular}{|c|c|c|}
\hline \multirow{2}{*}{ Index } & \multicolumn{2}{|c|}{ Value of index for compound } \\
\hline & Abamectin & Emamectin benzoate \\
\hline Chemical formula & $\mathrm{C}_{48} \mathrm{H}_{72} \mathrm{O}_{14}+\mathrm{C}_{47} \mathrm{H}_{70} \mathrm{O}_{14}$ & $\mathrm{C}_{56} \mathrm{H}_{81} \mathrm{NO}_{15}+\mathrm{C}_{55} \mathrm{H}_{79} \mathrm{NO}_{15}$ \\
\hline $\lg K_{0 / w}$ & 4.4 & 5.0 \\
\hline Water solubility, mg/L & 0.02 & 24.0 \\
\hline Solubility in organic solvents, g/L & $\begin{array}{c}\text { toluene }-23 \\
\text { acetone }-72 \\
\text { ethyl acetate }-160 \\
\text { octanol }-83\end{array}$ & $\begin{array}{c}\text { n-hexane }-0.077 \\
\text { toluene }-26 \\
\text { methanol }-2700 \\
\text { octanol }-48\end{array}$ \\
\hline $\mathrm{K}_{\mathrm{oc}}$ & 6633 & 377000 \\
\hline $\mathrm{DT}_{50}$ in soil, day ${ }^{1}$ & $1.54 \pm 0.05$ & $<1.0$ \\
\hline $\mathrm{DT}_{50}$ in soil, day ${ }^{2}$ & $1.0-1.8$ & $0.3-2.6$ \\
\hline $\mathrm{LD}_{50}$ per os, mg/kg & 8.7 & 81.5 \\
\hline GUS $^{1}$ & 0.03 & -0.03 \\
\hline GUS² & 0.01 & -0.66 \\
\hline
\end{tabular}

1 - data obtained in the soil and climatic conditions of Ukraine;

2 - literature data (BPDB, 2019);

$\mathrm{K}_{\mathrm{o} / \mathrm{w}}$ - octanol-water partition coefficient at $\mathrm{pH} 7,20^{\circ} \mathrm{C}$;

$K_{o c}$-soil organic carbon sorption coefficient;

$D T_{50}$ - half-life period;

$L D_{50}$ - median lethal dose (50\% of exposed animals died) 
1 - highly persistent ( $\mathrm{DT}_{50}$ over 100 days), 2 - moderately persistent $\left(\mathrm{DT}_{50}=30-100\right.$ days), 3 - low persistent $\left(\mathrm{DT}_{50}\right.$ less than 30 days).

Forecasting of the possibility of investigated insecticides migration in groundwater in soil and climatic conditions of Ukraine and other European countries was carried out according to a number of indicators.

Groundwater ubiquity score (GUS) (Gustafson, 1989) was calculated by the Eq. 1:

$G U S=\log D T_{50} \times\left[4-\log K_{o c}\right]$

Where: $\mathrm{DT}_{50}$ - persistency (half-life period) in soil, days; $\mathrm{K}_{\mathrm{oc}}$ - soil organic carbon sorption coefficient.

If the GUS value was $>2.8$, pesticide is likely to be leached into groundwater; if $1.8-2.8$, then the possibility of pesticide leaching into groundwater is insignificant; if $<1.8$, pesticide is not likely to be leached into groundwater (Gustafson, 1989).

For an integrated assessment of the potential danger of pesticide exposure to the human body after consumption of water from surface and groundwater supply sources, a scale of four gradations was used. It includes the LEACH (index of potential contamination of groundwater and river waters), half-life period ( $\mathrm{DT}_{50}$ ) in water and an allowable daily dose (ADD) or acceptable daily intake (ADI) (Table 2) (Antonenko et al., 2015; Novohatska, 2018).

After adding all the points received, the integral index of water hazard (IIWH) was evaluated as follows: if the value of IIWH equals to 3 or 4 points, substances are low hazardous to humans (class 4); IIWH 5 or 6 - moderately hazardous (class 3); IIWH 7 or 8 - hazardous (class 2); IIWH 9 or 10 - highly hazardous (class 1B); IIWH 11 or 12 - extremely hazardous (class 1A) (Antonenko et al., 2015; Novohatska, 2018).

The index of potential contamination of groundwater and river waters LEACH was calculated according to the Eq. 2 (Spadotto, 2002):

$L E A C H_{\text {mod. }}=\frac{S_{w} \times D T_{50 \text { field }}}{K_{o c}}$.

Where: $S_{w}$ - water solubility, $\mathrm{mg} / \mathrm{L}$; $\mathrm{DT}_{50 \text { field }}$ - half-life period in soil in field conditions; $\mathrm{K}_{\mathrm{oc}}$ - soil organic carbon sorption coefficient.

Assessment of the index: 0.0-1.0 - low risk of water contamination (class 3), 1.1-2.0 - average (moderate) risk of water contamination (class 2), > 2.0 - high risk of water contamination (class 1) (Spadotto, 2002).

Table 2. Scale of integrated assessment of the potential danger of pesticides exposure to the human body after consumption of water from surface and groundwater supply sources (Antonenko et al., 2015; Novohatska, 2018)

\begin{tabular}{|c|c|c|c|c|}
\hline \multirow{2}{*}{ Index } & \multicolumn{4}{|c|}{ Evaluation in points depends on index value } \\
\hline & 1 & 2 & 3 & 4 \\
\hline LEACH, y. o. & $<0.01$ & $0.01-0.1$ & $0.11-1.0$ & $>1.0$ \\
\hline $\mathrm{DT}_{50}$ in water, days & $<5$ & $5-10$ & $11-30$ & $>30$ \\
\hline ADD/ADI, mg/kg & $>0.02$ & $0.0051-0.02$ & $0.0021-0.005$ & $\leq 0.002$ \\
\hline
\end{tabular}

\section{Results and discussion}

The main chain of pesticide migration in the objects of the environment is ground-groundwater, surface water, and one of the main sources of their penetration into the human body is water. That is why we carried out an assessment of the risk of the probability of groundwater and river water contamination with investigated insecticides by the LEACH index in soil-climatic conditions of Ukraine and other European countries (Table 3).

In assessing potential leaching in different soil and climatic conditions according to the LEACH index (Table 3), it was established that for both studied substances there 
Table 3. Parameters of water persistence, migration ability and influence on the human body of the studied insecticides

\begin{tabular}{|c|c|c|c|c|}
\hline \multirow{2}{*}{ Index } & \multicolumn{2}{|c|}{ Abamectin } & \multicolumn{2}{|c|}{ Emamectin benzoate } \\
\hline & Index value & Points & Index value & Points \\
\hline LEACH $^{1}$ & $4.64 \times 10^{-6}$ & 1 & $6.37 \times 10^{-5}$ & 1 \\
\hline LEACH $^{2}$ & $5.43 \times 10^{-6}$ & 1 & $1.66 \times 10^{-4}$ & 1 \\
\hline $\mathrm{DT}_{50}$ in water, day ${ }^{3}$ & 2.4 & 1 & 8.7 & 2 \\
\hline $\mathrm{ADD}^{1}, \mathrm{mg} / \mathrm{kg}$ & 0.0002 & 4 & 0.001 & 4 \\
\hline $\mathrm{ADI}^{2}, \mathrm{mg} / \mathrm{kg}$ & 0.0012 & 4 & 0.005 & 3 \\
\hline IIWH', points & \multicolumn{2}{|c|}{6} & \multicolumn{2}{|c|}{7} \\
\hline $\mathrm{IIWH}^{2}$, points & \multicolumn{2}{|c|}{6} & \multicolumn{2}{|c|}{6} \\
\hline Evaluation of hazard & \multicolumn{2}{|c|}{$\begin{array}{l}\text { moderately hazardous } \\
\quad(\text { class } 3)^{1,2}\end{array}$} & \multicolumn{2}{|c|}{$\begin{array}{c}\text { hazardous (class } 2)^{1} \\
\text { moderately hazardous (class 3) }\end{array}$} \\
\hline
\end{tabular}

1 - data obtained in the soil and climatic conditions of Ukraine;

2 - literature data (BPDB, 2019);

3 - degradation in the water phase of the water-sediment system

is a very low risk of leaching (contamination) into groundwater and surface water $(\mathrm{LEACH}<1.0)$. This is due to their low solubility in water, high values of the soil organic carbon sorption coefficient and low soil persistence.

For abamectin, the solubility in water and $\mathrm{K}_{\mathrm{oc}}$ are lower than for emamectin benzoate. However, when LEACH is calculated by the Equation 2 (one in the numerator and the other in the denominator), they do not give a significant difference. It is also worth noting that according to the Koc, both compounds are not mobile (SSLRC classification, 1997). Although there is a difference in solubility (insoluble abamectin and slightly soluble emamectin), it does not significantly affect a very low value of the LEACH, in both cases assigned 1 point. That is, in general, although there is a difference in the solubility and sorption of the two compounds, it is not significant in the calculation and evaluation of this index.

When comparing the obtained results with the data calculated for other insecticides (Novohatska et al., 2018; Antonenko et al, 2016), it has been established that avermectins in the environment behave in the same way as most insecticides, which according to the LEACH index value have a low risk of leaching into groundwater and surface waters. This is due, first, to the low solubility in water of most of insecticides.

According to the Hygienic Classification of Pesticides (Pesticides: Hazard Classification, 1998), both compounds are not persistent in soil (hazard class 4). In our field studies, it was established that already on the day of treatment the concentration of the studied substances in the soil was very low due to their extremely rapid metabolism. For 2-4 days, the residual amounts of abamectin and emamectin benzoate in the soil of treated areas were not detected.

By SSLRC classification (SSLRC Classification, 1997), both compounds by the half-life period also belong to low persistence in the soil, while by the $\mathrm{K}_{\mathrm{oc}}$ value, they are non-mobile in soil. By water solubility, abamectin is not soluble, and emamectin benzoate is slightly soluble.

Both substances are persistent in the water-sediment system (class 1 of hazard according to the Hygienic Classification of pesticides): $\mathrm{DT}_{50}$ of abamectin -89 days, emamectin benzoate $>120$ days (BPDB, 2019). But they are low persistent in the water phase: abamectin pertains to class 4 of hazard (DT ${ }_{50}$ is 2.4 days (BPDB, 2019)) and emamectin benzoate pertains to class 3 of hazard $\left(D_{50}\right.$ is 8.7 days (BPDB, 2019)). This indicates the rapid transition of the compound from the aqueous phase to the sediment and the binding to it, which is explained, inter alia, by the high values of $\mathrm{K}_{\mathrm{oc}}$.

Taking into account high probability of groundwater contamination when introducing insecticides into the soil at different depths, we carried out an assessment of the risk of such a probability using the GUS index (Table 1) 
in the soil and climatic conditions of Ukraine and other European countries.

It was established that after application of pesticide formulations based on abamectin and emamectin benzoate in the soil and climatic conditions of Ukraine and other European countries, the studied compounds were not likely to be leached into groundwater.

For comparison, when pesticide formulations based on insecticides chlorpyrifos, dimethoate, bifentrine, cypermethrin, alpha-cypermethrin, lambda-cyhalothrin, tebufenpyradu and novaluron are applied in soil and climatic conditions of Ukraine, the latter are not likely to be leached into groundwater; in case of thiamethoxam, imidacloprid, chloranthraniliprole, the risk of leaching is low. The risk of leaching in soils of other European countries after application of chlorpyrifos, dimethoate, bifentrine, cypermethrin, alpha-cypermethrin, lambda-cyhalothrin, tebufenpyrad and newluron is low (probably not leachate), while in case of thiametoxam, imidacloprid, and chloranthraniliprole, it is very high (Novohatska et al., 2018; Antonenko et al., 2016; IntechOpen, 2019). The difference in the risk of potential thiamethoxam, imidacloprid, and chloranthraniliprole leaching from soils of Ukraine and other European countries can be explained by a significant difference in their soil resistance caused by difference in soil characteristic (Vavrinevych et al., 2015).

It is worth noting that the risk of groundwater contamination with insecticides is much lower than for fungicides and herbicides, in both soil and climatic conditions in Ukraine and in other European countries (Novohatska et al., 2018; Antonenko et al., 2016; IntechOpen, 2019; Antonenko et al., 2016; Vavrinevych, 2015).

It was established that abamectin, as in soil and climatic conditions of Ukraine, as well as other countries of Europe and the world, is moderately hazardous (class 3 ) for human consumption of contaminated drinking water according to the integral index of water hazard (IIWH) (Table 3). Emamectin benzoate by the IIWH value in the soil and climatic conditions of Ukraine is hazardous (class 2), while in other countries of Europe and the world, it is moderately hazardous (class 3 ) (Table 3). The results obtained can be explained by the high toxicity of both compounds (the values of ADD/ADI at the level of thousands and ten thousand of $\mathrm{mg} / \mathrm{kg}$ ) and at the same time low persistency in the objects of the environment.

For comparison, all previously investigated pyrethroid and pyrazole (chlorananthraniliprole chemical class) insecticides by the integral index of water hazard are hazardous to humans; all investigated neonicotinoids, organophosphate chlorpyrifos, and pyrazole tebufenpyrad are highly hazardous, dimethoate is extremely hazardous, and novalurone is moderately hazardous. It correlates with results obtained in our study.

However, the results obtained for other insecticides, in contrast to avermectins, can be explained by relatively high persistence in water and soil, and for some compounds by high probability of leaching into groundwater and surface water (Novohatska et al., 2018; Antonenko et al., 2016; IntechOpen, 2019). The values of ADD/ADI for them are somewhat lower than for avermectins (Novohatska et al., 2018; Antonenko et al., 2016; IntechOpen, 2019).

\section{Conclusions}

1 It was established that in the soil and climatic conditions of Ukraine and other European countries, abamectin and emamectin benzoate after application of formulations on their basis for processing agricultural crops are probably not leached into groundwater according to the ground ubiquity score (GUS).

2 It was shown that in different soil and climatic conditions, according to the LEACH index, which is significantly less than 1 for both investigated substances, there is a very low risk of groundwater and surface water contamination. This is due to their relatively high solubility in water, low soil persistence and very high values of the organic carbon sorption coefficient.

3 According to the IIWH index (integral index of water hazard), abamectin and emamectin benzoate in different soil and climatic conditions are moderately hazardous for a person after consumption of contaminated drinking water (class 3 ); emamectin benzoate in the soil and climatic conditions of Ukraine is hazardous (class 2). Such results are due to the high toxicity of abamectin and emamectin benzoate and, at the same time, low persistence in water and low probability of groundwater and surface water contamination. 
4 Given the high toxicity and the mechanism of action of the studied insecticides (direct effects on the nervous system), as well as the high hazard to human health after consumption of water contaminated with insecticides with extremely low persistence in the environment, it is necessary to carefully monitor the boundaries of sanitary-protective areas from treat- ed areas to water bodies, and control the process of exploitation of water supply sources, especially decentralized in rural areas. In regions with intensive agricultural production, it is recommended to use the IIWH index (integral index of water hazard) to make a decision about necessity of monitoring research on insecticides in water.

\section{References}

Antonenko A.M., Vavrinevych O.P., Korshun M.M. et al. (2019). Development of a Method for Prediction of Risk of Surface and Groundwater Contamination with Pesticides and Their Dangerous Aspects for Human Health. Groundwater - Resource Characterisation and Management Aspects. United Kingdom: IntechOpen, 37-50. https://doi.org/10.5772/intechopen.83600

Antonenko A.M., Vavrinevych O.P., Omelchuk S.T. et al. (2015). Prediction of pesticide risks to human health by drinkingwater extracted from underground sources. Georgian Medical News. 7-8 (244-245): 99-106.

Antonenko A.M., Vavrinevych O.P., Omelchuk S.T. et al. (2016). Comparative hygienic risk assessment of groundwater contamination by herbicides of different chemical classes and hazard prediction for human after consumption of contaminated water. Journal of Education, Health and Sport. 9: 873-882.

BPDB (Bio-Pesticide Properties Data Base) (2019). Abamectin. Available at: https://sitem.herts.ac.uk/aeru/bpdb/Reports/8. htm (assessed 18 June 2019).

BPDB (Bio-Pesticide Properties Data Base) (2019).Emamectin benzoate. Available at: https://sitem.herts.ac.uk/aeru/bpdb/ Reports/1326.htm. (assessed 18 June 2019).

Claudia A. Spadotto (2002). Screening method for assessing pesticide leaching potential. Pesticidas: R. Ecotoxicol. 12: 69-78. https://doi.org/10.5380/pes.v12i0.3151

Deepu David, Ige Abraham George \& John Victor Peter (2007). Toxicology of the newer neonicotinoid insecticides: Imidacloprid poisoning in a human. Clinical Toxicology. 45 (5): 485-486. https://doi.org/10.1080/15563650701338229

Eloisa Dutra Caldas (2008). ABAMECTIN (177), University of Brasilia, Brazil, $128 \mathrm{p}$.

EU - Pesticides database: Maximum Residue Levels (2019). Available at: http://ec.europa.eu/food/plant/pesticides/max residue_levels/index_en.htm. (assessed 17 June 2019).

Grafton-Cardwell E., Godfrey L., Chaney W. et al. (2005). Various novel insecticides are less toxic to humans, more specific to key pests. Calif. Agr. 59 (1): 29-34. https://doi.org/10.3733/ ca.v059n01p29

Gustafson D.I. (1989). Groundwater ubiquity score: a simple method for assessing pesticide leachability. Environmental Toxicology and Chemistry. 8: 339-357. https://doi.org/10.1002/ etc. 5620080411

International Initiative on Water Quality (IIWQ) (2019). Available at: https://en.unesco.org/waterquality-iiwq/wq-challenge. (assessed 19 June 2019).

List of pesticides and agrochemicals authorized for use in Ukraine. (2012). The official edition. Kyiv: Univest Media, 832 p.

List of pesticides and agrochemicals authorized for use in Ukraine. (2018). The official edition. Kyiv: Univest Media, 1036 p. Mode of action of incecticide. IRAC classification on mode of action (2014). Available at: http://www.irac.info. (assessed 17 June 2019).

Novohatska O.O., Stavnichenko P.V., Kondratiuk M.V. et al. (2018). Comparative hygienic evaluation of behavior of different pesticides groups in soil, prediction of risk of ground water contamination and its danger for human health in areas with irrigation farming. Rawal Medical Journal. 43 (1): 129-136.

Pesticides. Hazard classification: DSanPiN 8.8.1.002-98. (1998). Coll. important official materials on sanitary and anti-epidemic issues. Kyiv, 2000. Vol. 9. Part 1. P. 249-266.

SSLRC classification: Soil Survey and land research center. (1997). Cranfield University, UK.

Vavrinevych 0., Antonenko A., Omelchuk S. et al. (2015). Prediction of soil and ground water contamination with fungicides of different classes according to soil and climate conditions in Ukraine and other European countries. Georgian Med News. 5 (242): 77-84.

Vavrinevych O.P., Antonenko A.M., Omelchuk S.T. et al. (2015). Prediction of soil and ground water contamination with fungicides of different classes according to soil and climate conditions in Ukraine and other European countries. Georgian Medical News. 5 (242): 73-84. ( 
World Water Assessment Program (UNESCO WWAP) 2017). Available at: http://www.unesco.org/new/en/natural-sciences/environment/water/wwap/facts-and-figures/all-factswwdr3/fact-15-water-pollution/. (assessed 19 June 2019).

Antonenko A.M., Vavrinevych O.P., Omelchuk S.T. et al. (2016) Porivnyal'na gigiyenichna ocinka stijkosti u g'runti ta ry'zy'ku zabrudnennya g'runtovy'x vod insekty'cy'damy' rizny'x ximichny'x klasiv i prognoz nebezpechnosti dlya lyudy'ny' pry' vzhy'vanni kontaminovanoyi vody' [Comparative hygienic assessment of soil resistance and risk of groundwater contamination by insecticides of different chemical classes and prognosis of danger to humans when using contaminated water]. Problemy' harchuvannya. 2 (45): 31 39. (in Ukrainian). 